J. Dairy Sci. 92:972-979

doi:10.3168/jds.2008-1605

(C) American Dairy Science Association, 2009.

\title{
Development of a twenty-one-component finite element distal hind limb model: Stress and strain in bovine digit structures as a result of loading on different floorings
}

\author{
C. Hinterhofer, ${ }^{\star 1}$ H. Haider,† V. Apprich, ${ }^{\star}$ J. C. Ferguson, ${ }^{\star}$ S. N. Collins, $\neq$ and C. Stanek ${ }^{\star}$ \\ ${ }^{*}$ Clinic for Orthopedics in Ungulates, University of Veterinary Medicine, 1210 Vienna, Austria \\ †Department for Applied Plastic Technology, Austrian Research Institute for Chemistry and Technology, 1030 Vienna, Austria \\ $\neq$ Centre for Equine Studies, Animal Health Trust, Newmarket, CB8 7UU, United Kingdom
}

\begin{abstract}
Finite element modeling is a unique way of introducing technical and material research into medical science. A bovine distal hind limb was scanned using computed tomography for geometric image capture and the data were subsequently divided (segmented) into 4 tissue types: bone, bone marrow, soft tissue, and the horn capsule. Material data from previous studies were integrated into the model. Flexor tendons were assembled as longitudinal structures starting at their cross-sectional areas at the height of the metatarsophalangeal joint, proceeding in the plantaro-distal direction and meeting the distal phalanx at the tuberculum flexorium. Three different flooring situations (full support floor, bearing weight in the abaxial half of the lateral claw and in the dorsal halves of both claws, respectively) were created to evaluate the effects of loading. Full support resulted in von Mises stress levels between 3.5 and 1.5 MPa for the osseous structures and some regions of the segmented soft tissue; stress patterns in the bulb and sole of the claw capsule (1.5 MPa) and in the floor $(0.5 \mathrm{MPa})$ were similar to pressure plate data in vivo and in vitro, with corresponding strain values of $2.4 \%$. Reduced support resulted in higher stresses (up to $\sim 8 \mathrm{MPa}$ ) in bones, claw capsules, and tendons; high strains $(\sim 11 \%)$ were found in the soft tissue, depending on how the floor was constructed. Although the models may still be anatomically improved, stress and strain calculations are possible with results comparable to related research, and the model shows interaction between the 2 digits. This possibly will help with further understanding of the biomechanical function of this 2-digit structure. With respect to clinical interpretation, reduced support to the bovine hind limb increases focal stress peaks in the different tissues, which may indicate a location of potential injury.
\end{abstract}

Key words: cattle, flooring, lameness, biomechanics

Received August 2, 2008.

Accepted October 13, 2008

${ }^{1}$ Corresponding author: christine.hinterhofer@vu-wien.ac.at

\section{INTRODUCTION}

Soundness of bovine limbs is essential for both animal welfare (Fregonesi and Leaver, 2001; Bergsten, 2004) and economic success in the dairy industry (Armory et al., 2008). The limb also represents the main site for stress- and housing-related injury (Flower and Weary, 2006; Capion et al., 2008). The interaction between limbs and flooring has been assessed by locomotion studies (Phillips and Morris, 2001) and the variation in weight bearing over time when standing on uncomfortable ground (Neveux et al., 2006). Claw pressure and ground reaction force measurements were taken by Telezhenko et al. (2008) and van der Tol et al. (2002). Of increasing interest, the finite element $(\mathbf{F E})$ analysis approach (Hinterhofer et al., 2005, 2006a; Franck et al., 2008), based on models of the claw capsules, contributes to the field. Despite the well-known importance of claw and floor interaction (Cook, 2003; Platz et al., 2007) and the intense research in this field, not all problems have been solved. A model for effectively analyzing the biomechanics not only of the claw capsules, but of the complex 2-digit structure is lacking at present.

The FE modeling technique is of particular relevance in the investigation of the functional mechanics of the foot including bones and soft tissue structures. It has already proven to be of great value in the field of human podiatry, where it has allowed a better understanding of the human foot (Antunes et al., 2008) and footwear performance (Cheung et al., 2007). For FE analysis of equine biomechanics, an equine digit was simplified to 32-components, of which 19 were represented as geometric components and the remaining 13 were represented by simplified loading and boundary constraints (Collins et al., 2009). Stress peaks within the effectively modeled deep digital flexor tendon corresponded with pathological findings and hoof capsular displacements were consistent with experimental data. Preliminary results of the bovine distal hind limb model (DHLM) have been published by Hinterhofer et al. (2006b).

To create an FE model, the geometry of the anatomical assembly has to be captured and accurately divided 
into several discrete, functionally relevant components (Beaupre and Carter, 1992). Having completed this anatomical discretization, each component is further subdivided (meshed) into a finite number of elements (the FE mesh). Subsequently, material properties are defined for each component; surface interactions between contacting components are also specified, and the loading and boundary conditions of the assembly are similarly defined. In this way, mathematical equations can be generated at each nodal intersection, thereby converting the mathematical problem from an infinite number of higher order equations to a finite number of simpler solvable equations.

In the current study, we hypothesize that established mechanical engineering technology, coupled with data obtained from advanced imaging techniques, can be used to generate an accurate FE model of the bovine hind limb, including bones, the claw capsules, the skin and functional flexor tendons. We further hypothesize that loading the DHLM on different flooring situations can provide valuable new insight for understanding the biomechanics of the complex 2-digit structure.

\section{MATERIALS AND METHODS}

A normative distal limb model was created from computed tomography $(\mathbf{C T})$ data of the left hind foot of a dairy cow with a body mass of $600 \mathrm{~kg}$. The scans were taken postmortem; the animal had been slaughtered for reasons other than this study. Normality was based on the absence of lameness and of visual signs on the leg indicative of orthopedic problems.

\section{Development of the DHLM}

Limb Preparation and CT Image Acquisition. The limb was dissected at the distal metatarsal bones and trimmed to recognized claw trimming standards (Toussaint-Raven et al., 1985). For storage, it was then deep frozen at $-18^{\circ} \mathrm{C}$ and slowly warmed to room temperature for the $\mathrm{CT}$ scanning. Computed tomography imaging (Figure 1) was performed using a Ray Scan 3D-CT (Walischmiller, Markdorf, Germany) at the Upper Austrian University of Applied Sciences in Wels. CT resolution was $244 \mu \mathrm{m}$ per voxel at 1,000 $\mathrm{mA}$ and $170 \mathrm{kV}$. A 0.15 -mm brass filter was used at an integration time at the detector of $500 \mathrm{~ms}$; the dissected limb was stabilized in an upright position using styrofoam blocks. Seven hundred twenty projections were made in the course of a $360^{\circ}$ rotation; integration time was $1 \mathrm{~s}$.

Anatomical Rationalization, Segmentation, and Surface Extraction. The complex anatomy of the bovine 2-digit-assembly was simplified by identifying the bones with their bone marrow, the claw cap-

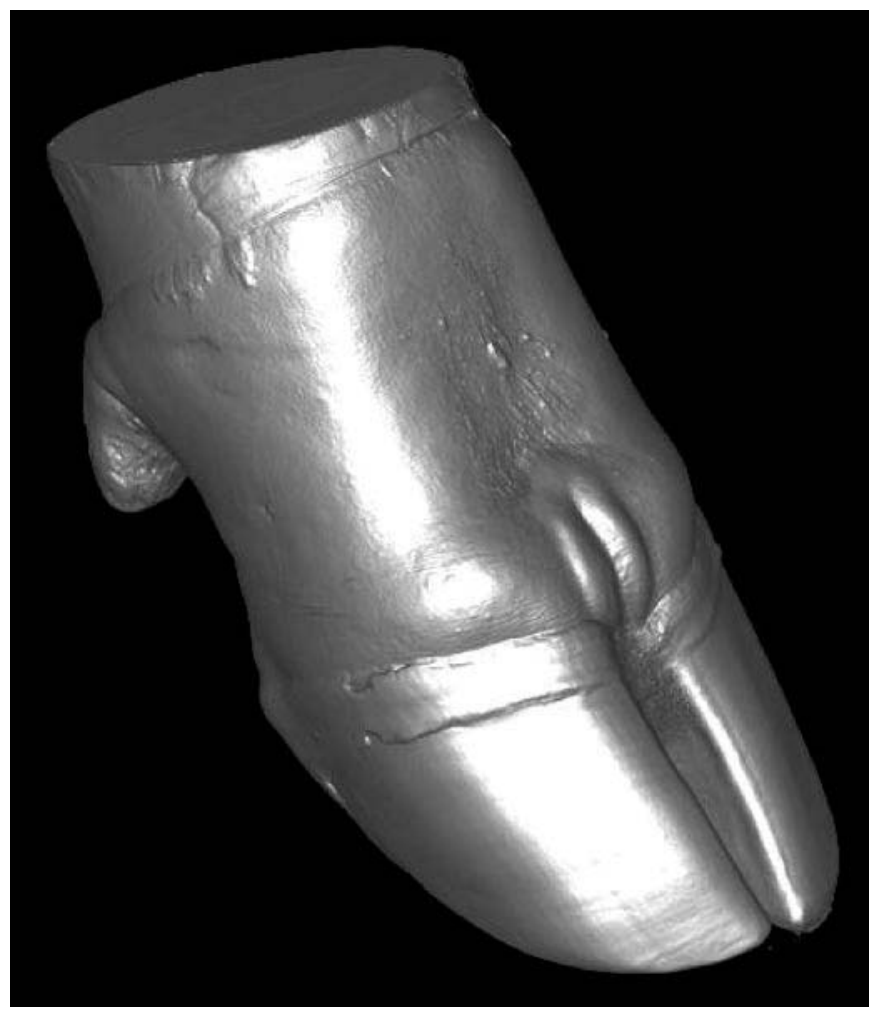

Figure 1. Image reconstruction of computed tomography data of cadaver limb specimen used for creation of the finite element distal hind limb model.

sules, and the skin. All other soft and connective tissues were integrated into the skin segment. Two longitudinal structures representing the flexor tendons were assembled (Figure 2) to stabilize against tilting. In total, this gave a simplified anatomy of 21 components (Table 1) requiring geometric representation.

Segmentation of the selected components was performed on the CT data set using the software VG Studio Max 1.2.1. (Volume Graphics GmbH, Heidelberg, Germany), based on user-defined gray scale levels and their gray scale connectivity. Extensive manual correction was needed before surface reconstruction from the standard triangulation language (STL format) surface mesh files were generated using the reverse engineering technique. Computer-aided design data, as a point cloud, was then produced using Pointmaster V4.5 (Knotenpunkt GmbH, Balingen, Germany) to create *.iges files of the same data, which could then be used for FE analysis.

Volume Mesh Generation and Model Assembly. Volume mesh generation and mesh integrity inspection was performed using ABAQUS simulation software (Simulia Abaqus Austria GmbH, Vienna, Austria) before further construction of the FE model assembly. Point cloud data was again divided into the selected segments and meshed separately. Bone marrow 


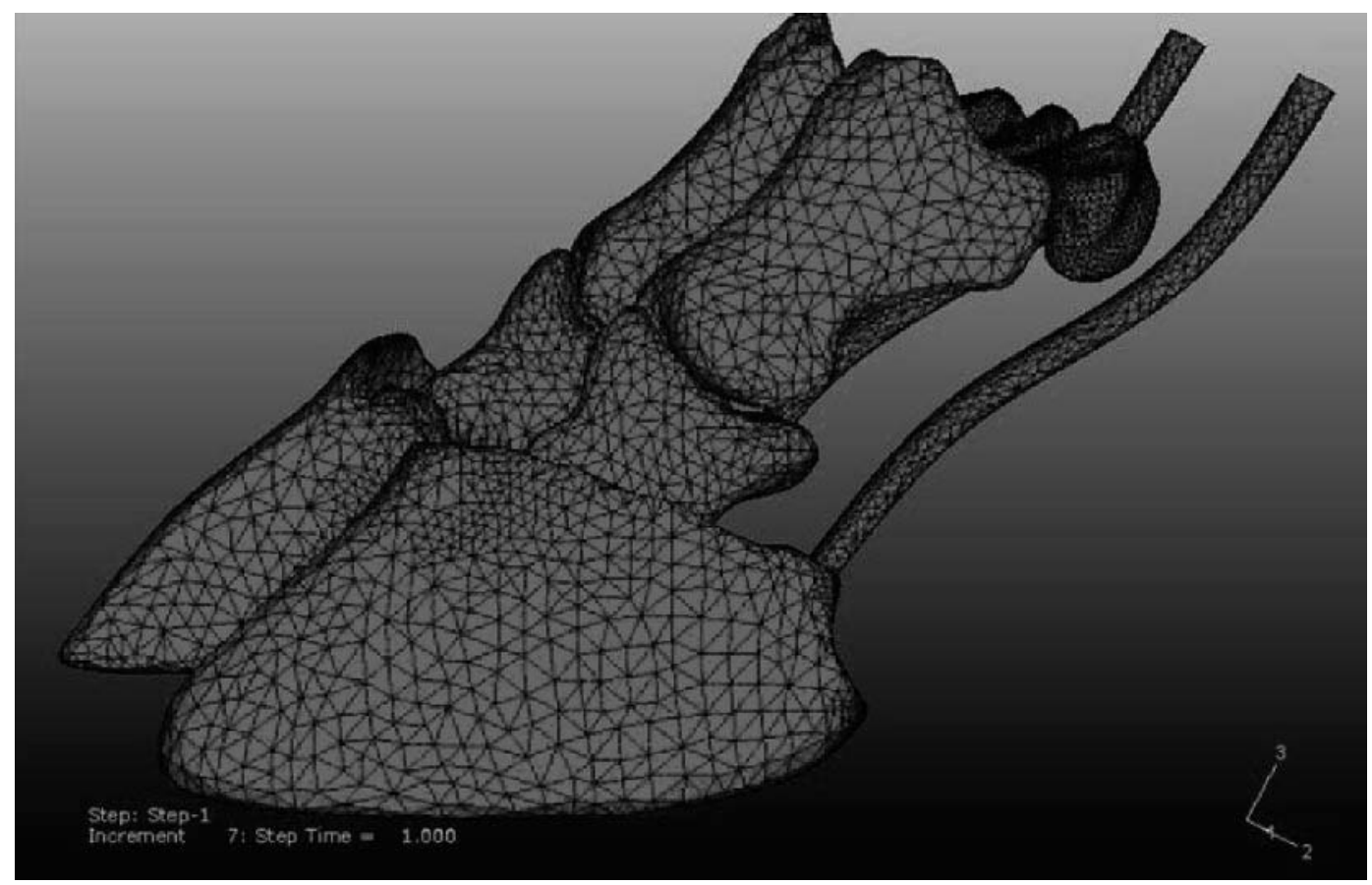

Figure 2. Distal hind limb model (partially displayed for better insight): bony structures, claw capsules, and functional flexor tendons. Metatarsus and soft tissues are hidden.

was defined as empty space. The bony structures were repositioned, as ready FE meshes, into the meshed soft tissue which, in turn, was placed into the claw capsule.

Assembly of the Flexor Tendons. The gray scale thresholding algorithms were not designed for selecting between the flexor tendons and the surrounding soft tissue structures. To cope with the absolute necessity of a longitudinal structure stabilizing against the backward rotation of the distal limb when loaded, flexor tendons had to be assembled. In each digit, starting at the cross-sectional area at the height of the metatarsophalangeal joint (MTPJ), a longitudinal element with exactly the cross-section data of both the superficial and deep digital flexor tendon was created to extend approximately $15 \mathrm{~mm}$ to the plantar aspect of the phalanges and to meet the tuberculum flexorium (TF) of the distal phalanx (P3), where it was fixed to the bony surface via spring elements.

Material Property Definition. The modulus of elasticity (E) and the Poisson's ratio were applied to

Table 1. Materials data and comments to 21 modeled components of finite element bovine digital hind limb model. All components were assigned linear elasticity and a Poisson's ratio of 0.3

\begin{tabular}{|c|c|c|c|c|}
\hline Tissue group & Component $^{1}$ & Components, $\mathrm{n}$ & $\begin{array}{c}\text { Modulus of } \\
\text { elasticity (MPa) }\end{array}$ & Comments \\
\hline \multirow[t]{4}{*}{ Bone } & P1 & 2 & 10,000 & Bone marrow inside; tied via surface contacts as tight junction to $\mathrm{s}$ \\
\hline & $\mathrm{P} 2$ & 2 & 10,000 & Bone marrow inside; tied via surface contacts as tight junction to $\mathrm{s}$ \\
\hline & ps & 4 & 10,000 & Solid structure; tied via surface contacts as tight junction to $\mathrm{s}$ \\
\hline & ds & 2 & 10,000 & Solid structure; tied via surface contacts as tight junction to s \\
\hline Bone marrow & bmP1 & 2 & 0 & Defined as having no mechanical function \\
\hline Tendon & $\mathrm{t}$ & 2 & 2000 & Tied with sliding algorithms to s; tied with spring elements to P3 \\
\hline Skin & $\mathrm{s}$ & 1 & 50 & $\begin{array}{l}\text { Large component including connective tissue, vessels and nerves } \\
\text { of skin, digital cushions, ligaments, extensor tendons, and joint } \\
\text { cartilages; tying algorithms see other components }\end{array}$ \\
\hline
\end{tabular}

${ }^{1} \mathrm{P} 1=$ proximal phalanx; $\mathrm{P} 2=$ medial phalanx; $\mathrm{P} 3=$ distal phalanx; ps = proximal sesamoid bone; ds = distal sesamoid bone; bmP1 = bone marrow of $\mathrm{P} 1$; bmP2 = bone marrow of $\mathrm{P} 2 ; \mathrm{mL}=$ claw capsule; $\mathrm{t}=$ tendon; $\mathrm{s}=$ skin. 
a

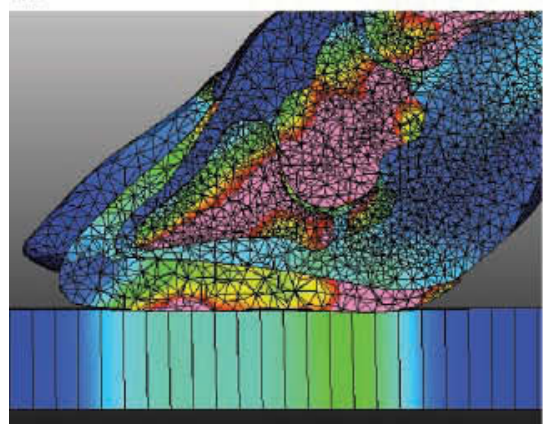

b

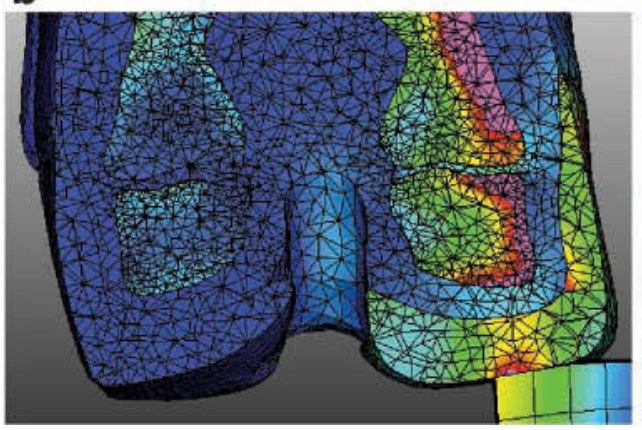

C

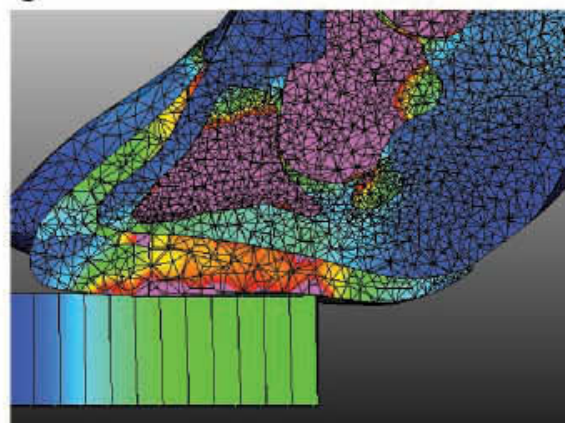

Figure 3. Stresses in the lower part of the distal hind limb model being a) fully supported (floor 1), b) supported only under the abaxial part of the lateral claw (floor 2, view from the front), c) supported in the dorsal aspects of both claws (floor 3). Red and pink areas represent stress values of $6.4 \mathrm{MPa}$ and above.

each component based on published data (Baillie et al., 2000; Franck et al., 2006; Apprich et al., 2008). Bony segments were defined with $\mathrm{E}=10,000 \mathrm{MPa}$ and the tendons with $\mathrm{E}=2,000 \mathrm{MPa}$. The claw capsule was given decreasing values of $600 \mathrm{MPa}$ for the dorsal wall, $400 \mathrm{MPa}$ for the abaxial wall and the quarters and $200 \mathrm{MPa}$ for the heels and the sole. The skin segment, including all other soft tissue structures, was assigned a value of $50 \mathrm{MPa}$, which is known to be high for skin, but in this case it also includes tendons and ligaments. All segments were attributed a Poisson's ratio of 0.3; and all elements were defined as having linear elastic properties.

The Floor. The floor was constructed as an even surface with $\mathrm{E}=10 \mathrm{MPa}$, and static friction between the claw capsules and the floor was defined at 0.6 ; both equivalent to values for a hard rubber mat.

Contact Surfaces and Boundary Conditions. Contact surface and boundary condition algorithms

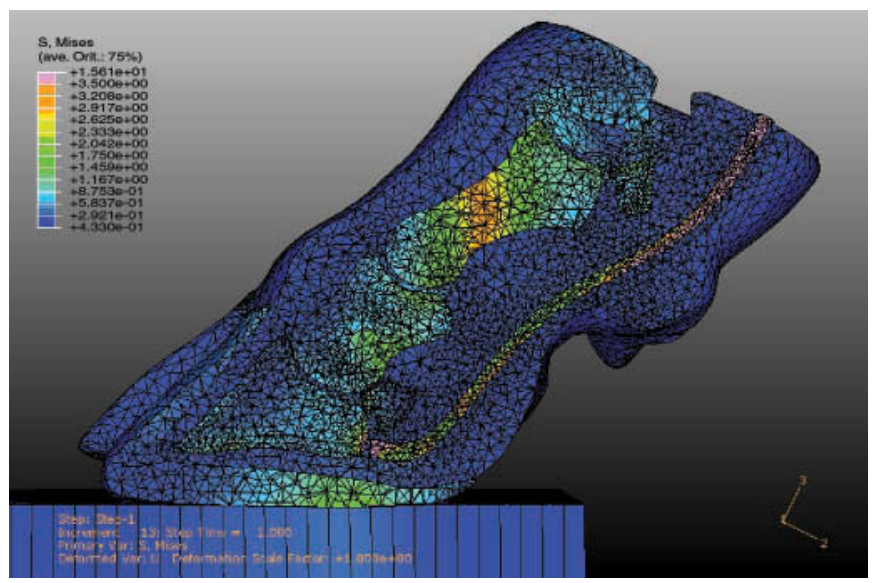

Figure 4. Stress of loaded distal hind limb model displayed as von Mises stress according to the scale in the left top corner; lateral digit is sectioned to enable evaluation of the desired cross-section.

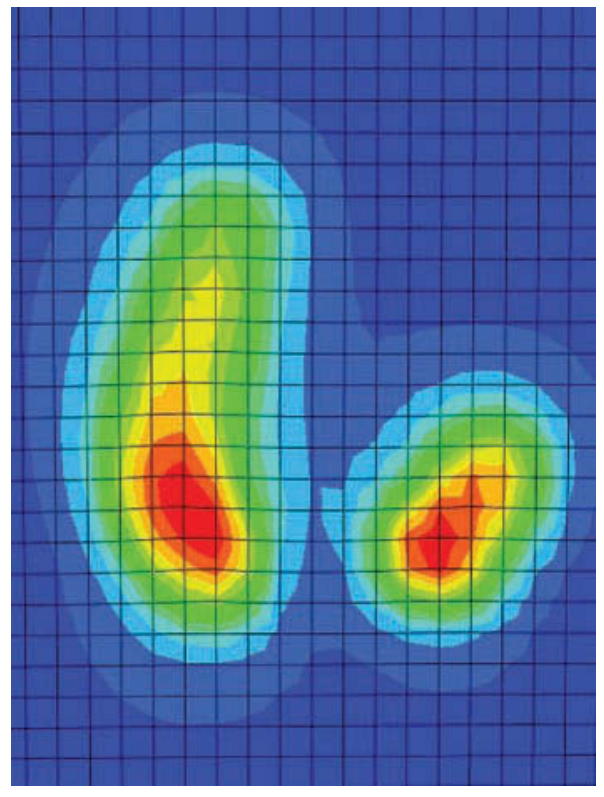

Figure 5. Stress in flat floor fully supporting the distal hind limb model (model is hidden): lateral claw has larger contact area (left in the picture) than smaller medial claw. Red color indicates maximum stress values of $0.5 \mathrm{MPa}$.

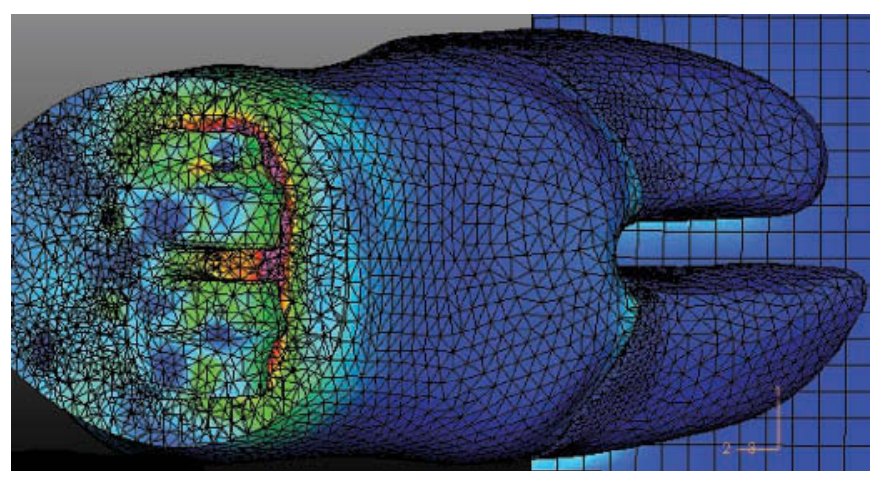

Figure 6. Strains in the dorsal soft tissue of the fetlock region of the distal hind limb model supported only in the dorsal aspect of both claws. Red and pink colored areas represent strains of $4 \%$ and above. 
were established to reproduce the surface-to-surface interactions within the DHLM. Components were tied via their surface contacts. Boundary conditions between bones and soft tissue and claw capsule were defined as tight junction. Surface interaction of the assembled flexor tendons and the surrounding soft tissue was established as a sliding action (Table 1).

\section{Analysis of the DHLM}

FE Simulations and Loading. Analyses were performed using ABAQUS standard solution simulation software. To accommodate for the relaxed dead limb positioning during the scanning procedure, initial prestraining simulations were performed by z-direction displacement of the proximal surface of the flexor tendons. Then, with the help of a reference point predicted in the center of the (missing) metatarsal bone, the load was applied by distributing vertical load vectors to the proximal joint surface of the proximal phalanges $(\mathbf{P 1})$ and the proximal sesamoid bones (ps). The reference point was restricted to vertical movement. Load was defined at 2,000 $\mathrm{N}$ for the joint surfaces of P1 and ps, and each of the flexor tendons were loaded with $250 \mathrm{~N}$ of traction force, resulting in a total load of 1,500 N (equivalent to $1 / 4$ body mass).

Different Floorings. For biomechanical comparison with other groups' research data, the model was loaded on a flat floor fully supporting both claws (floor 1; Figure 3a), on a floor supporting only the abaxial part of the lateral claw (floor 2; Figure $3 \mathrm{~b}$ ), and on a floor supporting only the dorsal halves of both claws (floor 3; Figure 3c). The interaction of floors and claws was calculated using static contact algorithms.

\section{RESULTS}

\section{Stress and Strain Analyses on Different Floorings}

On Floor 1. Peak von Mises stress levels above 3.5 $\mathrm{MPa}$ were found in the flexor tendons at their origin to P3 and along the MTPJ. The other parts of the tendons showed stresses up to $3.5 \mathrm{MPa}$, as did the midshaft of P1, especially in the abaxial corticalis (Figure 4). On closer observation, the claws, the region of the dorsal and axial coronary band, the claw sole underlying the TF and slightly plantar to the tip of P3, and the axial lamina gave stresses of $2.5 \mathrm{MPa}$ and below. Levels of strain up to $2.4 \%$ were calculated in the plantar region of the claw sole/bulb and neighboring soft tissue, specifically in the region around $\mathrm{TF}$ and the flexor tendons as they curve around the distal sesamoid bones. The soft tissue distal to the apical region of P3 showed strains of up to $1.7 \%$. Soft tissue mimicking the cartilages in the distal (DIPJ) and proximal (PIPJ) interphalangeal joints gave strain levels between $1.7 \%$ and $3.3 \%$. The plantar region of the fetlock showed the greatest strains, caused by the flexion of the MTPJ as a result of the applied load. Projected ground pressure distribution patterns were similar to patterns measured in vivo with pressure peaks of $0.5 \mathrm{MPa}$ below the bulbar region (Figure 5).

On Floor 2. von Mises stresses had the following pattern: both flexor tendons showed stress values of $7 \mathrm{MPa}$ and above, with the medial tendon showing high stresses only in the proximal section. The lateral (supported) digit had highest stresses in the abaxial corticalis of P1 (6.4 MPa) followed by the same pattern in P2 and P3, but the medial (nonsupported) digit also showed stress values of approximately $4 \mathrm{MPa}$ in the corresponding bony structures. The claw capsule of the supported digit showed highest stresses in the abaxial claw wall (4 MPa) and also intermittently over the whole run of the coronary band. Very high levels of strain (11\%) were calculated in the soft tissue between the digits, in the MTPJ, in all abaxial soft tissue structures of the supported digit and in the cartilage of the DIPJ and the PIPJ. The nonsupported digit is relatively free of strain with the exception of the MTPJ region. The projected ground pressure distribution pattern reflected the reduced support area and showed maximum stress levels of 0.5 MPa.

On Floor 3. Maximum stress levels rise above 8 $\mathrm{MPa}$ in both flexor tendons and stay slightly below 4 $\mathrm{MPa}$ in $\mathrm{P} 1$ and $\mathrm{P} 2$, but this time predominantly in the dorsal aspects. Peaks of $8 \mathrm{MPa}$ and above are found in all dorsal aspects of the MTPJ and neighboring soft tissue. Evaluating the claws, the sole/bulb area is highly stressed $(2.5 \mathrm{MPa})$, as is the coronary band. Large strains (4\%) are found in the soft tissue underlying the tip of P3, in all joint cartilages and in the soft tissues of the plantar aspects of both digits. Strains rise above $4 \%$ in the dorsal aspect of the MTPJ (Figure 6). Projected ground pressure distribution patterns again reflected the reduced support area. Peak von Mises stresses reached $0.8 \mathrm{MPa}$ at the edge of the floor under both claws.

\section{DISCUSSION}

This study represents the first occasion in which a sophisticated high resolution FE model of a bovine distal hind limb including bones, tendons, and soft tissue has been generated from advanced imaging modalities.

\section{Limb Preparation and CT Image Acquisition}

The significance of FE models is largely dependent on the quality of the geometrical data used. The styrofoam 
blocks for positioning the dissected extremity for the CT scanning were able to retain the limb in the desired angle to the ground. Problems arose concerning the oblique position of the metatarsal bone, and the medial claw. Attempts were made to rotate the modeled distal section of the metatarsal bone to an upright position to mimic bone column alignment at mid-stance. Too much interference with the modeled soft tissue of the MTPJ was the result; the metatarsus was finally taken out and the load was distributed evenly at the joint surfaces of P1 and the ps bones, to accomplish vertical loading. Second, the smaller medial claw was slightly tilted upwards because of the dissected tendons. This resulted in a higher loading of the lateral claw. Although not intended, this phenomenon can also be seen in the natural hind limb. A purpose made jig for the scanning procedure (Collins et al., 2009) and straining of the flexor tendons of the cadaver specimen would lessen, if not eliminate, these difficulties. This approach must be considered in any future work.

\section{Anatomical Simplification and Assembly of Flexor Tendons}

The objective of any modeling technique is to achieve a simplified yet realistic representation of reality. Because of software limitations, automated segmentation of soft tissue structures such as ligaments, joint capsules, tendons, and connective tissues from the rest of the skin was not achievable. Manual segmentation of these structures would have by far exceeded any possible project time. To compensate for the missing ligamentous structures, material properties of the skin segment were raised to $\mathrm{E}=50 \mathrm{MPa}$, which resulted in proper bone alignment when loaded, but still led to an undesired backward rotation of the 2 digits. This was opposed by the assembly of a longitudinal structure mimicking the flexor tendons and their function. Loading the model then resulted in imprints comparable to pressure plate results in vivo (van der Tol et al., 2002) and in vitro (Zeiner et al., 2007; Telezhenko et al., 2008), with a slight flexion of the PIPJ, as also found in loaded bovine digits.

\section{FE Meshing and Materials Properties}

The remesh algorithms were able to generate a high quality FE surface mesh. It represented an optimal balance between resolution of the models and the computational cost (time) of performing the simulations. The accuracy of the calculations is further dependant on appropriate materials characterization. As in all previous FE models in veterinary science, the DHLM has been built on the underlying assumption of linear elasticity, which is known to be incorrect. Nonlinear responses for the tissues, and the inclusion of orthotropic and viscoelastic characteristics would further improve the accuracy of any future simulation.

\section{The Choice of Flooring}

Flooring options were selected to deliberately create situations in which focal stress concentrations would occur within the weightbearing surface of the claw. This was done to gain understanding of the stress strain responses within the internal structures of the limb under different flooring regimens. There is no specific industry context in the background, but results should be used to improve welfare and soundness of dairy cows.

\section{Quasi-Static Weightbearing on a Fully Supporting Floor}

The stress distribution patterns within the medial and lateral digits were found to be in agreement with the results of van der Tol et al. (2004), who reported that in hind limbs between 70 and $80 \%$ of the total force was taken up by the lateral claw and between 20 and $30 \%$ by the medial claw. Looking more closely at the claw sole, highest stresses were found in the bulbar region of the outer claw, which coincides with clinical findings and in vitro pressure plate results of Zeiner et al., (2007). Absolute stress values of the claw capsules stayed below those measured in specimen trials by Franck and De Belie (2006). Floor imprints showed a pressure distribution comparable to selected results of Telezhenko et al. (2008), who measured 127 cows. The outcome of the DHLM is limited to a comparison with bovine distal limbs similar in size and conformation, but not necessarily for all anatomical or even pathological forms.

\section{Quasi-Static Weightbearing with the Model's Claws Being Only Partially Supported}

The reduced contact area raises pressure concentrations not only in the claw capsule, but also in bones and tendons. Compared with the fully supported DHLM, tendon stress peaks rose from $3.5 \mathrm{MPa}$ to 8 MPa and above. Within the claw capsules in floor 2, highest stresses were seen along the sagittal midline of the lateral claw, especially in the soft bulb. Floor 3 shifted the loading of the FE model limb to all dorsal aspects. The areas of the claw capsules in which these maximum pressures take place are known to be highly susceptible to injuries and pain (Dyer et al., 2007). This could point to the connection between the site of pressure peaks and claw diseases found in clinical 
observations. Floor imprints showed footprints similar to the reduced area of contact.

\section{Validation}

It is essential to validate models. This is particularly complex in the living organism, as it is difficult to allow for all experimental variables. Simple preliminary validation was performed by comparing the imprints on the floor using the presented calculations to corresponding research as mentioned above. Additional in vitro trials will contribute a more sophisticated method for validation and work is already in progress. Optical motion capture and strain mapping will provide fullfield data in response to simulated weightbearing. This will then be compared with data derived from an FE model of the same cadaver digit with the subsequent goal of performing it on the bovine 2-digit structure.

\section{CONCLUSIONS}

Finite element modeling, as a sophisticated engineering device, has still not reached its ultimate goal concerning analysis of organs and tissues. Further investigation and improvement is needed, especially with regard to material properties, which are known to be anisotropic or at least oriented and which still had to be defined as isotropic during modeling. Nevertheless, the DHLM, when comparing the output to related in vivo and in vitro studies, gave corresponding results where comparison was possible. We are of the opinion that this allows careful but positive interpretation of stresses and strains of deeper lying materials and structures, which are difficult to access by means other than FE analysis. When comparing the loaded model on different floors, the fully supported DHLM is exposed to the smallest amounts of stress and strain, whereas reduced support raises stress and strain in clinically interesting structures. This leads to the recommendation that stringent efforts should be made to avoid edges and uneven flooring in dairy flooring to minimize mechanical insults to the digits.

\section{ACKNOWLEDGMENTS}

This study was part of the EU Framework 5 Project "Lame Cow" QLK5-CT-2002-00969 and ongoing analysis is supported by the Austrian Science Fund (FWF project V56-N14). We gratefully acknowledge the staff of the Upper Austrian University of Applied Sciences in Wels for their part in this study.

\section{REFERENCES}

Antunes, P.-J., G. R. Dias, A. T. Coelho, F. Rebelo, and T. Pereira. 2008. Non-linear finite element modeling of anatomically detailed
3D foot model. http://www.materialise.com/materialise/view/ en/394365-Non-Linear+Finite+Element+Modelling+of+Anatomi cally + Detailed $+3 \mathrm{D}+$ Foot + Model.html

Apprich, V., C. Hinterhofer, E. Polsterer, J. C. Ferguson, and C. Stanek. 2008. Is moisture really the most important influencing factor on the mechanical properties of claw horn? Modulus of elasticity and dry-matter content in flat and contracted claws. Berl. Munch. Tierarztl. Wochenschr. 121:95-101.

Armory, J. R., Z. E. Barker, J. L. Wright, S. A. Mason, R. W. Blowey, and L. E. Green. 2008. Associations between sole ulcer, white line disease and digital dermatitis and the milk yield of 1824 dairy cows on 30 dairy cow farms in England and Wales from February 2003-November 2004. Prev. Vet. Med. 17:381-391.

Baillie, C. A., C. Southam, A. Buxton, and P. Pavan. 2000. The structure and properties of bovine hoof horn. Adv. Compos. Lett. 9:101-112

Beaupre, G. S., and D. R. Carter. 1992. Finite element analysis in biomechanics. Pages 149-174 in Biomechanics: Structures and Systems - A Practical Approach. A. A. Biewener, ed. IRL Press at Oxford University Press, Oxford, UK.

Bergsten, C. 2004. Healthy feet require cow comfort 24 hours. Pages 186-191 in Proc. 13th Int. Symp. and 5th Conf. on Lameness in Ruminants. Maribor, Slovenia.

Capion, N., S. M. Thamsborg, and C. Enevoldsen. 2008. Conformation of hind legs and lameness in Danish Holstein heifers. J. Dairy Sci. 91:2089-2097.

Cheung, J. T. M., B. Bouchet, M. Zhang, and B. M. Nigg. 2007. A 3D finite element simulation of foot-shoe interface. Pages $45-46$ in Proc. 8th Footwear Biomechanics Symp. E. C. Frederick and S. W. Yang, ed., Taipei, Taiwan.

Collins, S. N., R. C. Murray, S. Kneissl, C. Stanek, and C. Hinterhofer. 2009. Thirty-two component finite element models of a horse and donkey digit. Equine Vet. J. doi:10.2746/042516409X395688

Cook, N. B. 2003. Prevalence of lameness among dairy cattle in Wisconsin as a function of housing type and stall surface. J. Am. Vet. Med. Assoc. 223:1324-1328.

Dyer, R. M., N. K. Neerchal, U. Tasch, Y. Wu, P. Dyer, and P. G. Rajkondawar. 2007. Objective determination of claw pain and its relationship to limb locomotion score in dairy cattle. J. Dairy Sci. 90:4592-4602.

Flower, F. C., and D. M. Weary. 2006. Effect of hoof pathologies on subjective assessments of dairy cow gait. J. Dairy Sci. 89:139146.

Franck, A., G. Cocquyt, P. Simeons, and N. De Belie. 2006. Biomechanical properties of bovine claw horn. Biosystems Eng. 93:459-467.

Franck, A., and N. De Belie. 2006. Concrete floor-bovine claw contact pressures related to floor roughness and deformation of the claw. J. Dairy Sci. 89:2952-2964.

Franck, A., B. Verhegghe, and N. DeBelie. 2008. The effect of concrete floor roughness on the interaction with bovine claws using finite element analysis. J. Dairy Sci. 91:182-192.

Fregonesi, J. A., and J. D. Leaver. 2001. Behaviour, performance and health indicators of welfare for dairy cows housed in strawyard or cubicle systems. Livest. Prod. Sci. 68:205-216.

Hinterhofer, C., V. Apprich, J. C. Ferguson, J. Kastner, H. Haider, and C. Stanek. 2006b. A finite element model of the full bovine digit. Pages 30-31 In Proc. 14th Int. Symp. and $6^{\text {th }}$ Conf. Lameness in Ruminants. Colonia del Sacramento, Uruguay.

Hinterhofer, C., J. C. Ferguson, V. Apprich, H. Haider, and C. Stanek. 2005. A finite element model of the bovine claw under static load for evaluation of different flooring conditions. N. Z. Vet. J. $53: 165-170$.

Hinterhofer, C., J. C. Ferguson, V. Apprich, H. Haider, and C. Stanek. 2006a. Slatted floors and solid floors: Stress and strain on the bovine hoof capsule analyzed in finite element analysis. J. Dairy Sci. 89:155-162.

Neveux, S., D. M. Weary, J. Rushen, M. A. von Keyserlingk, and A. M. de Passillé. 2006. Hoof discomfort changes how dairy cattle distribute their body weight. J. Dairy Sci. 89:2503-2509. 
Phillips, C. J. C., and I. D. Morris. 2001. The locomotion of dairy cows on floor surfaces with different frictional properties. J. Dairy Sci. 84:623-628.

Platz, S., F. Ahrens, E. Bahrs, S. Nüske, and M. H. Erhard. 2007. Association between floor type and behaviour, skin lesions, and claw dimensions in group-housed fattening bulls. Prev. Vet. Med. 16:209-221.

Telezhenko, E., C. Bergsten, M. Magnusson, M. Ventorp, and C. Nilsson. 2008. Effect of different flooring systems on weight and pressure distribution on claws of dairy cows. J. Dairy Sci. 91:1874-1884.

Toussaint-Raven, E., R. T. Haalstra, and D. J. Peterse. 1985. Trimming. Pages $75-106$ in Cattle Foot Care and Claw Trimming. E. Toussaint-Raven, R. T. Haalstra, and D. J. Peterse, ed. Farming Press, Ipswich, UK. van der Tol, P. P. J., J. H. M. Metz, E. N. Noordhuizen-Stassen, W. Back, C. R. Braam, and W. A. Weijs. 2002. The pressure distribution under the bovine claw during square standing on a flat substrate. J. Dairy Sci. 85:1476-1481.

van der Tol, P. P. J., S. S. van der Beek, J. H. M. Metz, E. N. Noordhuizen-Stassen, W. Back, C. R. Braam, and W. A. Weijs. 2004. The effect of preventive trimming on weight bearing and force balance on the claws of dairy cattle. J. Dairy Sci. 87:17321738.

Zeiner, H., H. Schobesberger, M. Skalicky, and C. Stanek. 2007. Effect of different claw trimming methods on the pressure distribution under the bovine claw-An in vitro study. Berl. Munch. Tierarztl. Wochenschr. 120:165-172. 